\title{
The Necessity of Upper Extremity Neurologic Examination while Evaluating Breast Pain
}

\author{
Ahmet K. Belli ${ }^{a}$ Funda Dinc Elibol $^{b} \quad$ Arsal Acarbas $^{c}$ Onder Ozcan ${ }^{a}$ \\ Ozcan Dere $^{\mathrm{a}}$ Cenk Yazkan $^{\mathrm{a}}$ Cenk Elibol $^{\mathrm{b}}$ Kursat Tosun ${ }^{\mathrm{d}}$ Okay Nazli $^{\mathrm{a}}$

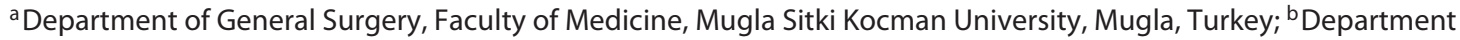 \\ of Radiology, Faculty of Medicine, Mugla Sitki Kocman University, Mugla, Turkey; 'Department of Neurosurgery, \\ Faculty of Medicine, Mugla Sitki Kocman University, Mugla, Turkey; ${ }^{d}$ Department of Biostatistics, Faculty of \\ Medicine, Mugla Sitki Kocman University, Mugla, Turkey
}

\section{Keywords}

Breast pain - Cervical root disorders - Differential diagnosis . Incidence - Mastalgia - Pain management - Quality of life

\begin{abstract}
Introduction: Breast pain is one of the most frequent complaints and occurs in 45-69\% of all women. Cervical disc herniation is a common cause of cervical radiculopathy with an incidence rate of 18.6 per 100,000 , and it should be considered as a cause of breast pain. Objective: To identify the extent to which upper extremity neurologic findings and cervical root disorders accompany breast pain. Methods: We prospectively collected clinical features of patients with breast pain. An upper extremity neurologic examination was performed in patients and controls. Patients who had neurologic findings underwent cervical spine magnetic resonance imaging (MRI) to identify cervical root disorders. Results: Out of the 554 participants, 233 had breast pain, and 321 were controls. Women with breast pain had more numbness (116 [49.8\%] vs. $104[32.4 \%], p<0.001)$ and more dysesthesia (36 [15.5\%] vs. 17 [5.3\%], $p<0.001)$ than the controls, but they had similar upper extremity weakness (10 [4.3\%] vs. 14 [4.4\%], $p>0.05)$. The number of women with one neurologic finding was significantly greater in the group with breast pain (119 [51.1\%] vs. 111 [34.6\%], $p<0.001)$. Ninety (16.2\%) patients underwent a cervical vertebra MRI, which showed
\end{abstract}

that $86(95.6 \%)$ patients had cervical root disorders including $21(23.3 \%)$ cases of bulging, 9 (10\%) of annular tear, and 56 (62.2\%) of central disc protrusion; 4 (4.4\%) patients had normal findings. The multivariate logistic regression analysis revealed that age was the only significant predictor of neurologic findings in patients with breast pain $(p<0.05$, OR: 1.02 , Cl: 1.002-1.053). Conclusions: Cervical root disorders should be considered as a cause of extramammary breast pain.

(c) 2020 S. Karger AG, Basel

\section{Introduction}

Breast pain is one of the most frequent complaints, which occurs in 45-69\% of all women in the reproductive age and leads them to consult primary care physicians, general surgeons, breast surgeons, or gynecologists for further evaluation $[1,2]$. In the past, breast pain was not seen as a symptom that required treatment because physicians thought that breast pain was a result of physiological changes and occurred in frustrated unhappy nulliparas [3]. In 1976, Preece et al. [4] classified breast pain into six groups: cyclic breast pain, ductal ectasia, Tietze's syndrome, trauma, sclerosing adenosis, and cancer. However, this classification was reduced to three groups consisting of cyclic breast pain, non-cyclic breast pain, and extramammary pain [5]. Cyclic pain is related to the men- 
strual cycle of a woman. It is usually bilateral and diffuse and occurs more in the luteal phase of the menstrual cycle in which breast swelling occurs. Non-cyclic pain is not related to menstrual cycle, can be unilateral in the breast and more common in women who are $40-50$ years of age $[6,7]$. Costochondritis, Tietze's syndrome, angina, rib injuries, and cervical root disorders are some of the causes of extramammary breast pain.

Cervical disc herniation is a common cause of cervical radiculopathy with an incidence rate of 18.6 per 100,000. The risk factors of the disease are male gender, heavy lifting, cigarette smoking, diving, and it peaks after the sixth decade of life $[8,9]$. Neck and arm pain are the cardinal symptoms of the disease. Conservative treatment including lifestyle changes is the first-line treatment of the disease, and approximately $26 \%$ of the cases require surgical intervention [10]. Dowle [11] was first to report that cervical root disorders should be considered as a cause of breast pain. Moreover, in our daily practice, we noticed that women with breast pain have a significant number of accompanying upper extremity neurologic findings which suggested cervical root disorders. However, there has been no study that reported the extent to which cervical root disorders accompany breast pain. The aim of this study is to identify the rate at which upper extremity neurologic findings and cervical root disorders accompany breast pain.

\section{Materials and Methods}

Patient Selection and Outcome Variables

We prospectively collected clinical features of patients who presented with breast pain to our institution's breast clinic after obtaining informed consent and ethical approval. A detailed patient history including past medical, family, gynecologic, obstetric and social history was taken in addition to the breast and upper extremity neurologic examination. Patients who were younger than 16 years old, male patients, or those who did not want to participate in the study were excluded. A control group was selected from women without breast pain and same variables were recorded for comparison.

\section{Assessment of Breast Pain}

We questioned location, intensity, quality, duration, frequen$\mathrm{cy}$, and radiation of the pain along with associated symptoms such as gastroesophageal reflux disease and neck or back pain. Pain intensity was determined by displaying a visual analog scale to each patient and asking them to score their pain. In the physical examination, all four quadrants of the breast were examined to find the tenderness site in addition to the axillae, head, and neck exam. Breast pain related to menses were determined as cyclic, and breast pain not related to menses was determined as non-cyclic. Mammography, breast sonography, or both were utilized depending on the patient's age to exclude any underlying pathology. Patients rescored their pain after 3-4 days of oral analgesic treatment.

Upper Extremity Neurologic Examination

We carried out an upper extremity neurologic examination for all patients. Pain or numbness in the upper extremity was ques- tioned, and any dysesthesia in the upper extremity like hypo- or hyperesthesia or any weakness in the upper extremity were recorded. Patients who had numbness or one of the neurologic findings were consulted with a neurosurgeon for further evaluation and underwent cervical spine magnetic resonance imaging (MRI). The control group was also evaluated with an upper extremity neurologic examination; however, no imaging studies were done because of the ethical format of the study.

\section{Statistical Analysis}

IBM SPSS Statistics Data Editor 22.0 was used to display frequencies and to perform the comparison. Initially, variables were categorized into categorical or scale data. For the scale data, the Shapiro-Wilks test was used to analyze normal distribution. Two categorical data were compared with the $\chi^{2}$ test and categorical and scale data were compared with an independent samples $t$ test if the distribution was normal. On the other hand, we run a non-parametric $t$ test if the distribution was not normal. Educational status was categorized into women whose education was less than high school grade or equal or more than high school grade. A univariate and multivariate logistic regression analysis was performed to find the significant variables related to the presence of the neurologic findings.

\section{Results}

Of the 554 participants, 233 had breast pain and 321 were controls. Regarding pain characteristics, 45 (19.3\%) had cyclic and 177 (76\%) non-cyclic breast pain. Sixtythree (27\%) had right, 117 (50.2\%) left, and 53 (22.7\%) bilateral breast pain. The pain was intermittent in 190 $(81.5 \%)$ of the patients, and the median duration of the pain was $3(0-365)$ months. The median pain VAS score was $5(0-10)$ points, and it decreased to $1(0-9)$ point after 3-4 days of oral analgesic treatment.

There were no differences in age (median 37 [12-76] vs. 36 [16-71] years), menopausal status (187 [80.3\%] vs. 248 [77.3\%] premenopausal), abortus (38 [16.3\%] vs. 53 [16.5\%], curettage [56 [24\%] vs. $61[19 \%])$ history, or accompanying gastroesophageal reflux symptoms (88 [37.8\%] vs. 99 [30.8]) $(p>0.05)$ between patients and controls.

Women with breast pain had a significantly greater prevalence of accompanying neck or back pain (156 [67\%] vs. $165[51.4 \%])$; they were more likely to have a live birth history (178 [76.4\%] vs. 214 [66.7\%]), and breastfeeding history (207 [88.8\%] vs. 200 [62.3\%]). Moreover, occupational status (87 [37.3\%] vs. 174 [54.2\%]) and educational level (95 [40.8\%] vs. 202 [62.9\%]) were lower in women with breast pain ( $p<$ 0.001). Regarding upper extremity neurologic findings, women with breast pain more frequently had numbness (116 [49.8\%] vs. 104 [32.4\%], $p<0.001)$ and dysesthesia (36 [15.5\%] vs. $17[5.3 \%], p<0.001)$ than the controls, but they had similar rates of upper extremity weakness (10 [4.3\%] vs. $14[4.4 \%], p>0.05)$. The presence of one of the 
Table 1. Clinical features of the patients with and without breast pain

\begin{tabular}{|c|c|c|c|}
\hline Clinical features/patients & $\begin{array}{l}\text { Breast pain group } \\
(n=233 ; 42.1 \%)\end{array}$ & $\begin{array}{l}\text { Control group } \\
(n=321 ; 57.9 \%)\end{array}$ & $p$ \\
\hline Age, years & $37(12-76)$ & $36(16-71)$ & 0.4 \\
\hline Gender (female) & $233(100)$ & $321(100)$ & NA \\
\hline Pain type & & NA & NA \\
\hline Cyclic & $45(19.3)$ & & \\
\hline Non-cyclic & $177(76)$ & & \\
\hline Missing & $11(4.7)$ & & \\
\hline Pain location & & NA & $\mathrm{N}$ \\
\hline Right breast & $63(27)$ & & \\
\hline Left breast & $117(50.2)$ & & \\
\hline Bilateral & $53(22.7)$ & & \\
\hline Median duration of pain, months & $3(0-365)$ & NA & NA \\
\hline Pain consistency & & NA & NA \\
\hline Constant & $42(18)$ & & \\
\hline Intermittent & $190(81.5)$ & & \\
\hline Initial pain score & $5(0-10)$ & NA & NA \\
\hline Pain score after treatment & $1(0-9)$ & $\mathrm{NA}$ & NA \\
\hline Neck or back pain & $156(67)$ & $165(51.4)$ & $<0.001$ \\
\hline Gastroesophageal reflux symptoms & $88(37.8)$ & $99(30.8)$ & 0.09 \\
\hline Menopausal status & & & 0.3 \\
\hline Premenopausal & $187(80.3)$ & $248(77.3)$ & \\
\hline Postmenopausal & $46(19.7)$ & $73(22.7)$ & \\
\hline Live birth history & $178(76.4)$ & $214(66.7)$ & 0.008 \\
\hline Abortus & $38(16.3)$ & $53(16.5)$ & 0.95 \\
\hline Curettage & $56(24)$ & $61(19)$ & 0.15 \\
\hline Breastfeeding history & $207(88.8)$ & $200(62.3)$ & $<0.001$ \\
\hline \multicolumn{4}{|l|}{ Occupational history } \\
\hline Housewife & $146(62.7)$ & $147(45.8)$ & $<0.001$ \\
\hline Employed & $87(37.3)$ & $174(54.2)$ & \\
\hline \multicolumn{4}{|l|}{ Educational background } \\
\hline None or primary school & $135(57.9)$ & $119(37.1)$ & $<0.001$ \\
\hline High school or university & $95(40.8)$ & $202(62.9)$ & \\
\hline Upper extremity numbness & $116(49.8)$ & $104(32.4)$ & $<0.001$ \\
\hline Upper extremity hypo-/hyperesthesia & $36(15.5)$ & $17(5.3)$ & $<0.001$ \\
\hline Upper extremity weakness & $10(4.3)$ & $14(4.4)$ & 0.97 \\
\hline Having one of the neurologic findings & $119(51.1)$ & $111(34.6)$ & $<0.001$ \\
\hline Cervical spine MRI & & NA & \\
\hline Normal & $4(4.4)$ & & \\
\hline Bulging & $21(23.3)$ & & \\
\hline Annular tear & $9(10)$ & & \\
\hline Protrusion & $56(62.2)$ & & \\
\hline
\end{tabular}

neurologic findings was significantly more frequent in the women with breast pain (119 [51.1\%] vs. 111 [34.6\%], $p<0.001)$. Ninety $(16.2 \%)$ patients underwent a cervical vertebra MRI, which displayed 86 (95.6\%) cervical root disorders including $21(23.3 \%)$ cases of bulging, 9 (10\%) of annular tear, and 56 (62.2\%) of central disc protrusion; $4(4.4 \%)$ patients had normal findings (Table 1$)$. The association between the presence of neurologic findings and breast pain was evaluated with univariate and multivariate logistic regression analysis, and we found that age was the only significant predictor $(p<0.05$, OR: $1.02 \mathrm{CI}$ :
1.002-1.053; Tables 2-3). The ROC curve analysis revealed an area under curve value of $0.61(p<0.05)$, and it displayed a cutoff value (sensitivity: $72.4 \%$, specificity: 53\%, likelihood ratio: 1.54) at age 32.5 (Fig. 1).

\section{Discussion/Conclusion}

This study showed that patients with breast pain had a significantly increased rate of upper extremity neurologic findings compared to the controls. To the best of our 
Table 2. Univariate logistic regression analysis to predict neurologic findings in patients with breast pain

\begin{tabular}{lcllc}
\hline \multirow{2}{*}{ Clinical features } & \multicolumn{4}{c}{ Univariate logistic regression analysis } \\
\cline { 2 - 5 } & beta & OR & $p$ & CI \\
\hline Age & 0.033 & 1.03 & $\mathbf{0 . 0 0 4}$ & $1.01-1.05$ \\
Pain duration & 0 & 1 & 0.69 & $1-1$ \\
Pain consistency & -0.3 & 0.75 & 0.41 & $0.38-1.48$ \\
VAS score & 0.08 & 1.1 & 1.8 & $0.96-1.22$ \\
Pain type (cyclic, & & & & \\
$\quad$ non-cyclic) & 0.08 & 1.1 & 0.81 & $0.56-2.1$ \\
Parity & 0.57 & 1.77 & 0.07 & $0.95-3.3$ \\
Abortus & 0.16 & 1.17 & 1.17 & $0.58-2.4$ \\
Curettage & -1 & 0.9 & 0.74 & $0.49-1.66$ \\
Breastfeeding & 0.66 & 1.94 & 0.16 & $0.77-4.88$ \\
Occupation & -0.5 & 0.07 & 0.07 & $0.35-1.03$ \\
Education & 0.61 & 1.83 & $\mathbf{0 . 0 3}$ & $1.07-3.13$ \\
\hline
\end{tabular}

Table 3. Multivariate logistic regression analysis to predict neurologic findings in patients with breast pain

\begin{tabular}{lllll}
\hline \multirow{2}{*}{$\begin{array}{l}\text { Clinical } \\
\text { features }\end{array}$} & \multicolumn{4}{l}{ Multivariate logistic regression analysis } \\
\cline { 2 - 5 } & beta & OR & $p$ & CI \\
\hline Age & 0.02 & 1.02 & $\mathbf{0 . 0 3}$ & $1.002-1.053$ \\
Education & -0.3 & 0.73 & 0.31 & $0.4-1.3$ \\
\hline
\end{tabular}

knowledge, there has been no study that reported the exact rate of upper extremity neurologic findings accompanying breast pain. Detailed patient history taking, including pain characteristics such as location, radiation, quality, intensity, duration, and frequency of the pain, and gynecologic and family history, must be performed as an initial step. Then, a comprehensive physical examination of the breasts, head and neck, and chest and heart and upper extremity neurologic examination should be done to determine the laboratory work to find the exact cause of the breast pain.

In our previous study, we found that a personal history of breast or gynecologic disease, or family history of breast cancer was the major reason for women with breast pain to visit breast clinics [12]. Since breast cancer is the most common cancer in women, many women have considerable concern about having breast cancer and they are followed by the screening programs such as close physical examination and mammography. The assumption of having breast cancer may be climaxed when the level of pain peaks, which may increase patients' anxiety level to the extent that they visit a breast clinic. Barros et al. [13] assessed the impact of reassurance on the breast pain and showed that it decreased the breast pain in $70.2-85 \%$ of the patients. Nevertheless, physicians usually focus on excluding breast cancer and reassuring the patients rather

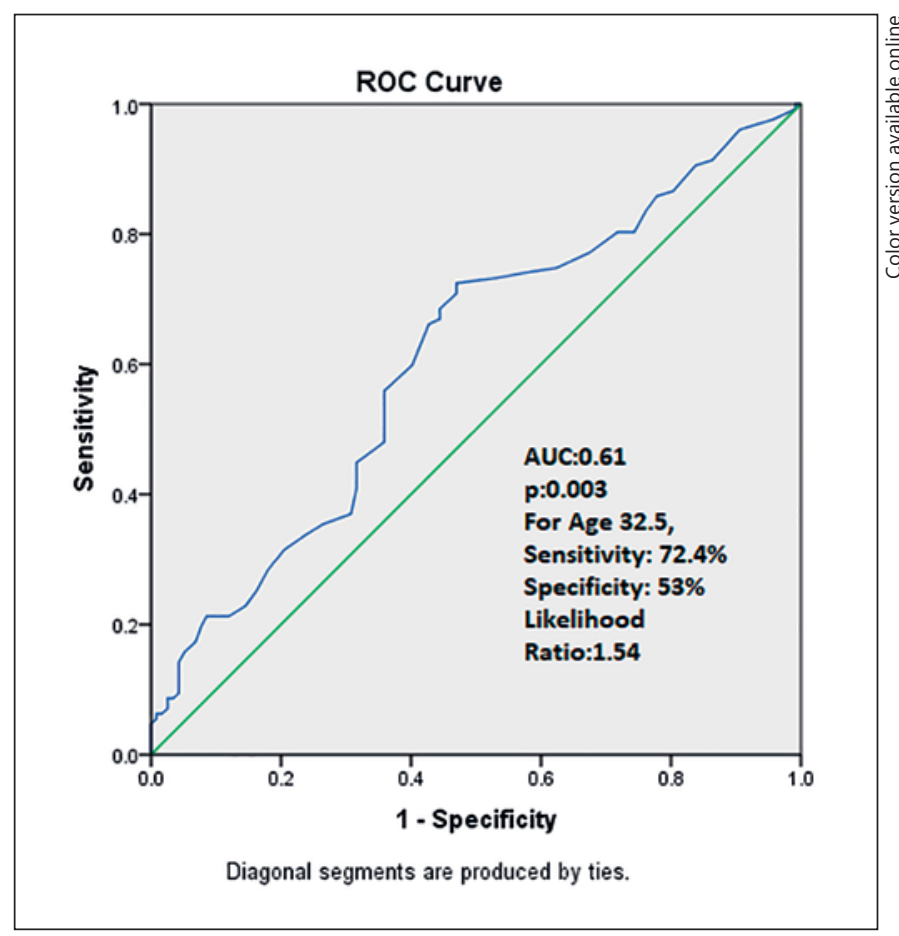

Fig. 1. ROC curve diagram of the variable age to predict neurologic findings in patients with breast pain. than finding the cause of breast pain. Therefore, extramammary causes of breast pain such as cervical root disorders have been generally omitted, and the patient could not be referred to any treatment that is specific to the cause. To our knowledge, this study has unique results on the rate of upper extremity neurologic findings and cervical MRI findings accompanying breast pain.

It is expected that nerve root pain should follow a specific dermatome, so that physicians can diagnose it as radicular pain. Radiculopathy is a term defined as a constellation of symptoms like paresthesia, hypoesthesia, anesthesia, and motor and/or sensory disturbance [14]. Patients with spinal pain can perceive the pain in a wider area than the expected site of origin which is called referred pain [15]. It is an axiom that nerve root pain or neurologic symptoms should follow a dermatomal distribution; however, some studies showed that it was not a strict rule [16-18]. Murphy et al. [19] investigated the distribution of pain by evaluating 226 nerve roots in 169 patients. They found that cervical nerve roots followed nondermatomal area in nearly two-thirds of the patients (69.7\%). Moreover, pain perceived around the scapulae was present in half of their patients. In our study, we found that neurologic findings were significantly more frequent in women with breast pain (119 [51.1\%] vs. 111 $[34.6 \%], p<0.001)$, and patients with neurologic findings 
had $95.6 \%$ of cervical disc disorders. Although breast pain dermatome area, $\mathrm{T} 4$ in the nipple, does not correspond to a cervical root disorder, we believe that referred pain, scapular area pain, or the periscapular area muscle tension may cause the breast pain. Moreover, stress occurring from either cervical root disorder or any external cause may tense up head and neck, upper extremity or chest muscles, so that it may give rise to extramammary breast pain. Furthermore, musculoskeletal symptoms may interact with physical or psychosocial conditions. Physical inactivity might also increase lower back, shoulder, and neck pain in this patient group [20]. In our study, the patients who had breast pain indicated that they might be physically inactive because they had more neck and back pain and lower educational levels, and less of them were employed.

In conclusion, this unique study showed that there was a considerable amount of cervical root disorders accompanying breast pain in women. If physicians include cervical root disorders in the differential diagnosis of the breast pain, question neurologic symptoms, and do an upper extremity neurologic examination, patients can be diagnosed more accurately and may be given alternative treatment such as physical therapy or spinal surgery.

\section{Statement of Ethics}

This research was conducted ethically in accordance with the World Medical Association Declaration of Helsinki. Patients and controls have given their written informed consent, and the study protocol was approved by the institute's committee on human research.

\section{Disclosure Statement}

The authors have no conflicts of interest to declare.

\section{Funding Sources}

None.

\section{Author Contributions}

Conception: A.K. Belli; design: A.K. Belli; supervision: A.K. Belli; materials: A.K. Belli, F. Dinc Elibol, O. Ozcan, O. Dere, C. Yazkan, C. Elibol, O. Nazli; data collection and processing: A.K. Belli, F. Dinc Elibol, O. Ozcan, O. Dere, C. Yazkan, C. Elibol, O. Nazli; analysis and interpretation: A.K. Belli, K. Tosun; literature review: F. Dinc Elibol, O. Ozcan, O. Dere, C. Yazkan, C. Elibol; writers: A.K. Belli, F. Dinc Elibol, O. Ozcan, O. Dere, C. Yazkan, C. Elibol, K. Tosun, O. Nazli; critical review: A.K. Belli.

\section{References}

1 Masood S, Ader DN, Shriver CD. Update on clinical and research issues in cyclical mastalgia. Breast J. 1998;4(1):25-32.

2 Scurr J, Hedger W, Morris P, Brown N. The prevalence, severity, and impact of breast pain in the general population. Breast J. 2014 SepOct;20(5):508-13.

3 Jeffcoate N. Principles of Gynaecology. London: Butterworths; 1975.

4 Preece PE, Mansel RE, Bolton PM, Hughes LM, Baum M, Gravelle IH. Clinical syndromes of mastalgia. Lancet. 1976 Sep; 2(7987):670-3.

5 Mansel RE. Management of Breast Pain. In: Harris JR, Lippman ME, Morrow M, Osborne $\mathrm{CK}$, editors. Diseases of the Breast. Philedelphia: Lippincott Williams \& Wilkins; 2010. p. 52-57.

6 Morrow M. The evaluation of common breast problems. Am Fam Physician. 2000 Apr; 61(8):2371-8

7 Eren T, Aslan A, Ozemir IA, Baysal H, Sagiroglu J, Ekinci O, et al. Factors Effecting Mastalgia. Breast Care (Basel). 2016 Jun;11(3): 188-93.
8 Radhakrishnan K, Litchy WJ, O’Fallon WM, Kurland LT. Epidemiology of cervical radiculopathy. A population-based study from Rochester, Minnesota, 1976 through 1990. Brain. 1994 Apr;117(Pt 2):325-35.

9 Wong JJ, Côté P, Quesnele JJ, Stern PJ, Mior SA. The course and prognostic factors of symptomatic cervical disc herniation with radiculopathy: a systematic review of the literature. Spine J. 2014 Aug;14(8):1781-9.

10 Carette S, Fehlings MG. Clinical practice. Cervical radiculopathy. N Engl J Med. 2005 Jul;353(4):392-9.

11 Dowle CS. Breast pain: classification, aetiology and management. Aust N Z J Surg. 1987 Jul;57(7):423-8.

12 Belli AK. Patient history includes effective factors to visit breast clinics for women with breast pain. 3rd Breast Cancer Conference; 2018; Istanbul.

13 Barros AC, Mottola J Jr, Ruiz CA, Borges MN, Pinotti JA. Reassurance in the treatment of mastalgia. Breast J. 1999 May;5(3): 162-5.

14 Wolff MW, Levine LA. Cervical radiculopathies: conservative approaches to management [vii.]. Phys Med Rehabil Clin N Am. 2002 Aug;13(3):589-608.
15 Seaman DR, Cleveland C 3rd. Spinal pain syndromes: nociceptive, neuropathic, and psychologic mechanisms. J Manipulative Physiol Ther. 1999 Sep;22(7):458-72.

16 Milette PC. Radiculopathy, radicular pain, radiating pain, referred pain: what are we really talking about? Radiology. 1994 Jul;192(1): 280-2.

17 Gifford L. Acute low cervical nerve root conditions: symptom presentations and pathobiological reasoning. Man Ther. 2001 May; 6(2):106-15.

18 Murphy DR. Cervical radiculopathy and pseudoradicular syndromes. In: Murphy DR, editor. Conservative Management of Cervical Spine Syndromes. New York: McGraw-Hill; 2000. p. 189-220.

19 Murphy DR, Hurwitz EL, Gerrard JK, Clary R. Pain patterns and descriptions in patients with radicular pain: does the pain necessarily follow a specific dermatome? Chiropr Osteopat. 2009 Sep;17(1):9.

20 Lundberg U, Dohns IE, Melin B, Sandsjö L, Palmerud G, Kadefors R, et al. Psychophysiological stress responses, muscle tension, and neck and shoulder pain among supermarket cashiers. J Occup Health Psychol. 1999 Jul; 4(3):245-55. 